SHORT COMMUNICATION

\title{
Wave record and flow regimes of the 2004 Indian Ocean tsunami in Sri Lanka
}

\author{
Ananda Gunatilaka \\ 10, Thumbovila, Piliyandala.
}

Submitted: 10 May 2009; Accepted: 17 July 2009

\begin{abstract}
Tsunami waves that impacted upon the coastline of Sri Lanka on the $26^{\text {th }}$ December 2004 were investigated with respect to their hydrodynamic interactions and resulting complex flow regimes. Field surveys showed that a large island with a narrow and steep continental shelf was subjected to destructive waves, which swept around a $900 \mathrm{~km}$ swathe of coastline from the eastern seaboard (facing the seismic source in Sumatra) to the western or shadow side with comparable magnitude and intensity. Waves impacted the coastline directly (orthogonally) and were also reflected and refracted according to the geomorphology of the coastline. Three waves of different magnitude and competence inundated the coastal plain as far as $2 \mathrm{~km}$ inland in about four hours. The maximum wave heights and run-up elevations exceeded $12 \mathrm{~m}$. Inundation was dependent on the direction of wave approach, coast to inland topography and the coastal bathymetry. The results generated by GPS-based mapping surveys define the flow regime of this megatsunami in Sri Lanka. They have an application in ongoing programmes of coastal community awareness and disaster management and can be utilized in planned evacuation procedures in a similar future scenario, thus minimizing loss of life.
\end{abstract}

Keywords: Bathymetry, coastal geomorphology, disaster awareness and planning, flow regimes, tsunami waves.

\section{INTRODUCTION}

On $26^{\text {th }}$ December 2004, a subduction thrust earthquake of magnitude $9.3 \mathrm{M}_{\mathrm{w}}$ in the Sunda Trench in Sumatra generated the first known trans-oceanic tsunami in the Indian Ocean, which affected 12 countries $^{1}$. In Sri Lanka, $1600 \mathrm{~km}$ to the west of the epicentre (Figure 1), the first of three tsunami waves struck the east coast a few minutes before 8.43 a.m. local time ( 3.13 hours GMT), with the second apparently more destructive wave a few minutes later causing severe damage on many parts of the coastline (Figure 2). Tide gauges around the Indian Ocean (including Sri Lanka) recorded water level variations over several days ${ }^{2}$. The shoaling waves generated a complex flow regime, with extensive inundation of the low coastal plain and deposited a sand-sheet $2-22 \mathrm{~cm}$ thick over an area of $\sim 120-140 \mathrm{~km}^{2}$. The lost and unaccounted for lives exceeded 39,000 in Sri Lanka, with over half a million people being displaced. Property and infrastructure damage was estimated at US\$ 2 billion. Around 4 million people inhabit a $1 \mathrm{~km}$ wide coastal zone.

An international tsunami survey team (ITST) made a rapid four day survey of selected coastal areas within two weeks of the event ${ }^{3}$. Also, four satellites (Quickbird, Topex/Poseidon, Jason1 and Terra) were able to record oceanographic data in the western Bay of Bengal region before, during and after the tsunami waves struck the island coastline. The flow behaviour of tsunami waves around Sri Lanka $\left(\sim 66,000 \mathrm{~km}^{2}\right.$ in area) on that day is described in this study.

The purpose of this investigation is to present an island wide comprehensive record of tsunami inundation, wave heights and run-up as the waves moved inland and withdrew (or dissipated). Such data are invaluable in deciphering the flow regimes of ancient tsunami analogues preserved in the geological record.

\section{METHODS AND MATERIALS}

During the first 3 months after the event, data were collected from over 200 localities (GPS fixed) on: inundation distances, maximum tsunami heights, standing water levels, maximum run-up heights on selected traverses, maximum landward extent of damage, eye-witness accounts, photographic records, etc. 
The approaches were based upon guidelines provided by the Intergovernmental Oceanographic Union ${ }^{4}$. The maximum wave heights and inundation boundaries were delineated on the basis of dead vegetation, flotsam, flow markers and material trapped in trees, together with damage to structures. Data were plotted using Arcview GIS (Figure 3). The presence of natural barriers, such as dunes and mangrove belts were noted. Two years after the 2004 event very little evidence of the wave impacts was preserved.

Terra images of offshore Sri Lanka also showed two types of internal wave patterns, linear and bow-waves (Figure 4). Linear patterns as seen on straight shelf edges are considered to be due to reflected waves; the bowwaves are present in the submarine canyons, confirming the correspondence between bathymetry and the observed patterns.

In simple sinusoidal surface gravity waves of small amplitude in very deep water, their rate of forward motion is directly dependent on the wavelength $(\square)$ and wave height and water depth $(H)$ play no role in determining wave speed. Deep-water wave theory fails when the ratio of $H$ to $\square$ falls below 0.5 . As these waves pass into shallow water (formally defined as $H<\square / 20$ ), they undergo attenuation due to bottom friction and result in significant motions at the bottom. When wave speed or celerity (C) becomes increasingly affected by $H$, the waves move with a velocity that is proportional to the square-root of $H$ and independent of $\square$ or period:

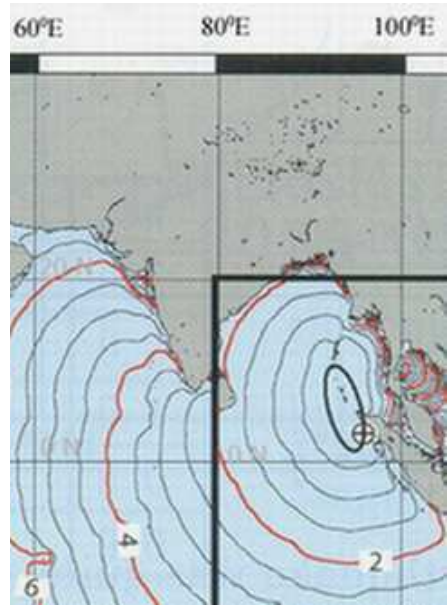

Figure 1: The travel-time map and propagation of the 2004 tsunami across the Indian Ocean. The contour intervals are in minutes and hours (red) since the earthquake occurred. The source region in the Sunda Trench is outlined.

Source: Japan Meteorological Agency, December 2004.

$$
C=\sqrt{ } g H
$$

Tsunamis are categorized as long-period surface gravity waves whose speeds are independent of $\square$. Their speeds are described by the generalized equations given below ${ }^{5}$.

$$
\begin{aligned}
& C_{s}=\sqrt{\frac{g}{k} \tanh (k H)} \\
& C_{s}=\frac{C_{g}}{2}\left\lceil\frac{1+2 k H}{\sinh 2 k H}\right\rceil
\end{aligned}
$$

For a tsunami, equations (1) and (2) can be approximated with $k H<<1$ to $C_{\mathrm{s}}=\sqrt{ } \mathrm{g} / H$ (i.e. the shallow water wave equation above); $C_{g}=C_{s} ; C_{g}$ is the group speed and $C_{s}$ is the phase speed of waves; $k$ is the wave number; $g$ is the

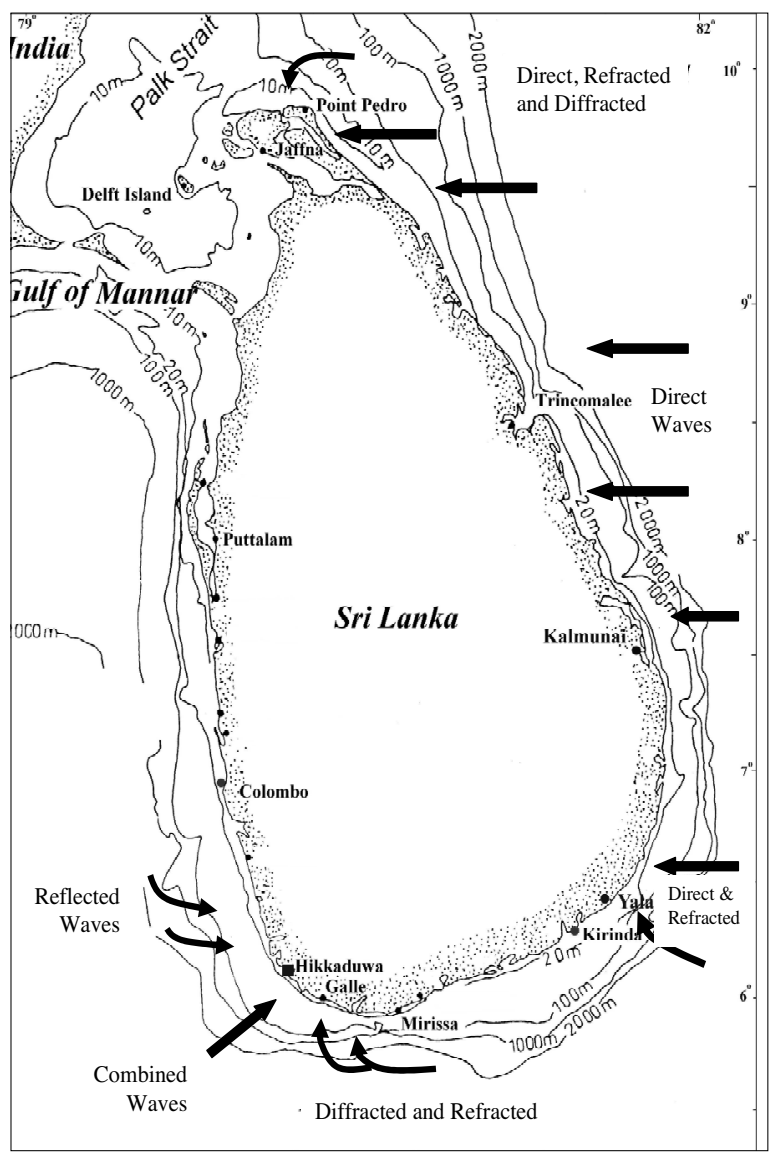

Figure 2: The bathymetry around Sri Lanka showing tsunami wave impacts. Note the narrow shelf and steep bathymetry. Wave diffraction was most prominent in the extreme north of the island, where the waves had to go through a narrow strait into the Gulf of Mannar. Base map courtesy of NARA

(Source: National Aquatic Resources Research and Development Agency) 
acceleration due to gravity and $H$ is water depth. If $H$ is known, wave speeds can be estimated.

Tsunami waves generated by mega-earthquakes (like the $9.3 \mathrm{M}_{\mathrm{w}}$ Sumatra-Andaman event) are sinusoidal in form with amplitudes $(h)<1 \mathrm{~m}$, wavelengths $(\lambda)$ of $10-800 \mathrm{~km}$ and periods $(t)$ of $100-5000$ seconds. Their wave speeds (celerities) on the open ocean are typically 160 to $250 \mathrm{~ms}^{-1}, 30-85 \mathrm{~ms}^{-1}$ on continental shelves and on the order of $10 \mathrm{~ms}^{-1}$ near the coast. As they pass over the narrow shelf into depths where bed-friction becomes important, their $\lambda$ become shorter, group together and gain height to form high walls of water with "maximum" flow velocities of 2 to $4 \mathrm{~ms}^{-1}$ near coasts (similar to large storm waves); these, in turn, were responsible for the destruction caused by onshore run-up and inundation.

As shallow-water waves are associated with coasts, they are also refracted (due to variation of wave speed with depth) and diffracted (as waves pass through narrow spaces between land areas such as islands). Tsunami waves are always reflected at the coast, with edge waves also being present. Resonant amplification of reflected waves, edge waves and incoming waves means that wave heights will vary substantially along a coastline and could double the height of an incoming wave.

Tsunami wave run-up $[H]$ is the land elevation at the furthest point of inundation with reference to a surveyed point on the coast. The parameters that can be determined from $[H]$ are: (i) tsunami magnitude $(\mathrm{m})$, which is defined as

$$
\mathrm{m}=\log _{2}[H]
$$

and, (ii) tsunami intensity (I), which is defined as:

$$
I=\log _{2}\left[2^{1 / 2} \cdot H\right]
$$

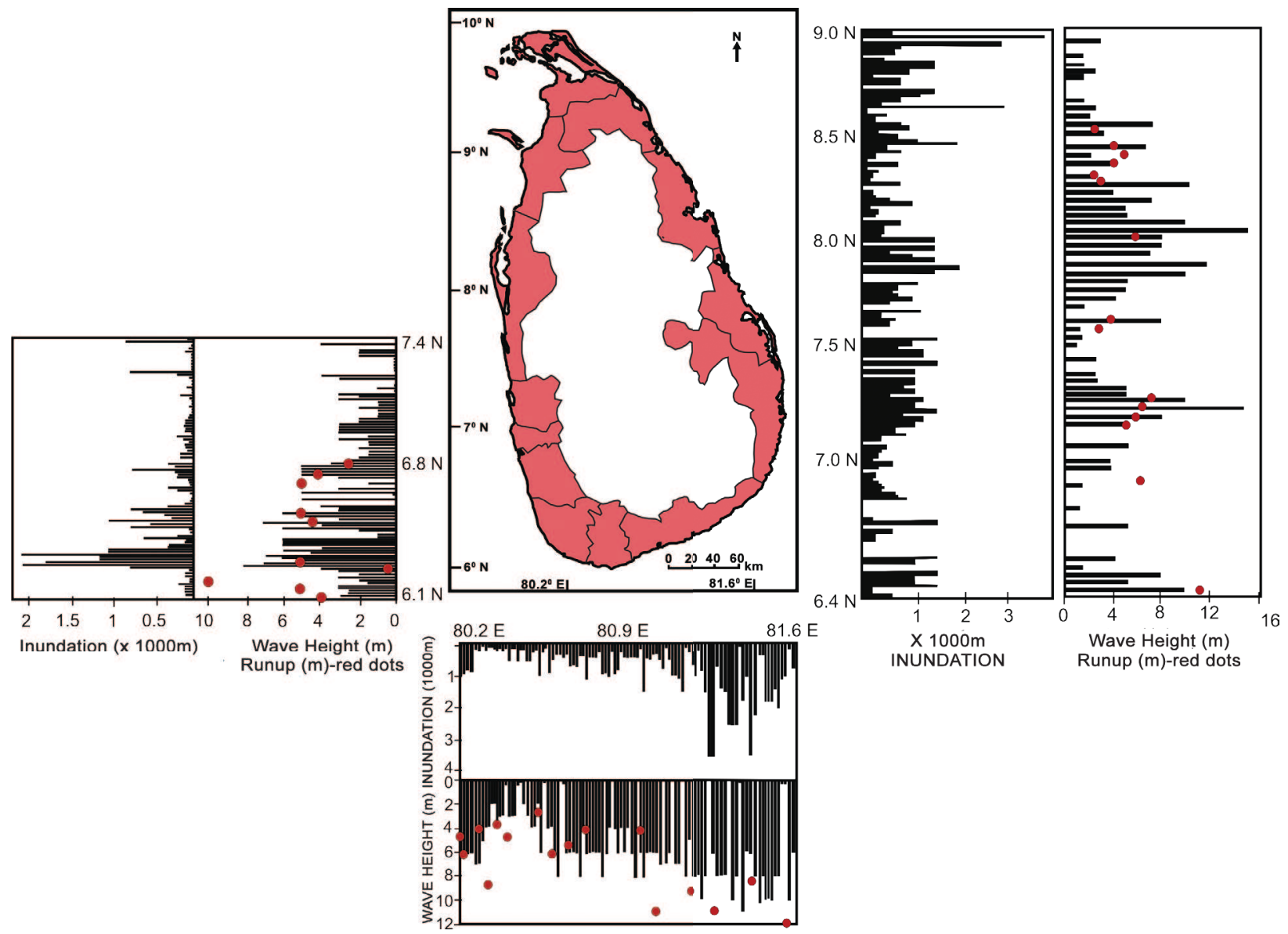

Figure 3: The pattern of inundation, tsunami wave heights and run-up elevations (GPS-fixed) of the 2004 tsunami around Sri Lanka. The coastline from $\sim 7.8^{\circ} \mathrm{N}$ to $9.7^{\circ} \mathrm{N}$ on the northwest coast was unaffected by the waves due to the shadow effect of the southern Indian landmass. The gaps in data in the extreme southeast is due to a well developed and extensive dune complex. The Jaffna Peninsula was inaccessible during the survey. 


\section{RESULTS AND DISCUSSION}

The hydrodynamic flow regime of the tsunami is a result of the interaction of the nearshore bathymetry and coastal geomorphology with the incoming waves. The waves impacted directly and were also refracted, reflected and occasionally diffracted as they traversed the coastline and resulting in combined flows (Figure 2). Following impact, the onshore wave record is represented by the maximum wave heights (and their magnitude and intensities), runups and inundation flooding (Figure 3).

A very narrow continental shelf surrounds Sri Lanka (2-25 km width and 30-90 m depth) and is bordered by a continental slope, which drops to over $2000 \mathrm{~m}$ within $30 \mathrm{~km}$ of the shoreline (Figure 2). Several submarine canyons and incised valleys occur at the shelf-slope margins. These are some of the world's steepest bathymetric features, with $>45^{0}$ slopes in some areas. In eastern Sri Lanka, where the tsunami waves initially impacted, the water depths decrease from $\sim 4000 \mathrm{~m}$ to $50 \mathrm{~m}$ within about $25 \mathrm{~km}$ of the coast. These features focused and transmitted the tsunami flows on to the shelf, eventually reaching the shoreline. Indeed, the initial tsunami strikes on the east coast (near Kalmunai) were associated directly with the trends and locations of the submarine canyons (Figures 2, 4).

Since waves before the run-up are controlled by shallow water wave dynamics, the bathymetry and coastal geomorphology govern their directions of propagation. Further, around seventy rivers and small streams flow into the affected coastal zone. Their estuarine channels were exploited by the tsunami waves, during both uprush and return flows. Depending on the relationship between coast and inland topographic gradients some areas developed new channel morphologies (where none existed previously) to drain sediment laden high velocity return flows, which formed small "delta-like" lobes in the nearshore regions. These ephemeral geomorphic features were evident on the west coast (especially near Kalutara) when the sea withdrew about $400 \mathrm{~m}$ after the first tsunami wave, which exposed the sea floor (as was depicted in Quickbird satellite imagery from DigitalGlobe Inc.).

The "recorded" tsunami waves and their times of impact around the coast are given in Table 1. The inundation, run-up and wave height records shown in Figure 3 refer to the strongest wave at any particular location. The maximum landward penetration of the tsunami wave (away from bays, lagoons, estuaries and harbours) was $2 \mathrm{~km}$ inland. The measured maximum wave and run-up heights were over $12 \mathrm{~m}$ and maximum standing water level marks on walls were over $4 \mathrm{~m}$. Most eye-witness observations indicated that unlike normal waves, which break on the shore, the stronger tsunami waves came in as a powerful surge and inundated coastal areas to varying distances inland. Mapping surveys showed that the main tsunami parameters were highly variable even within very short distances $(<100 \mathrm{~m})$. In Sri Lanka, which is surrounded by a relatively flat and wide coastal plain, inundation distances, wave heights and run-ups were dependent upon several local factors. The nearshore bathymetry, the focusing of tsunami wave energy, the presence or absence of mangroves, fringing coral reef platforms, angle and direction of wave approach, shape of the coastline, presence of artificial coastal barriers and coastal dune complexes, topographic profiles and coastal gradients were among these. Despite this variability, there was still good correlation between inundation distances and wave heights (Figure 3). Runup elevations did not always show a clear relationship to wave heights.

Whilst much of the east coast was hit directly by the waves (the second wave was generally the highest and, by inference, the strongest and most destructive in this sector), to the south of these locations, the waves were partitioned into direct and refracted components. The southern and western shorelines were subjected to a very complex combined flow pattern of refracted,

Table 1: Impact times (local) of the tsunami waves around Sri Lanka on $26^{\text {th }}$ December 2004 from several eye-witness accounts (only source).

\begin{tabular}{llll}
\hline $\begin{array}{l}\text { Location } \\
\text { (See Figure 2) }\end{array}$ & $\begin{array}{c}\text { Wave 1 } \\
\text { (time a.m.) }\end{array}$ & $\begin{array}{c}\text { Wave 2 } \\
\text { (time a.m.) }\end{array}$ & $\begin{array}{l}\text { Wave 3 } \\
\text { (time a.m.) }\end{array}$ \\
\hline Jaffna & $9.05-9.20$ & $9.30-9.50^{*}$ & $?$ \\
Trincomalee & $8.50-9.00$ & $9.00-9.20^{*}$ & $9.40 ?$ \\
Batticaloa & $8.50-9.05$ & $9.00-9.15^{*}$ & $9.35-$ \\
Kalmunai & $8.30-8.45$ & $8.55-9.15^{*}$ & $9.30-9.50$ \\
Yala & $9.20-9.30$ & $9.35-10.00^{*}$ & $?$ \\
Hambantota & $9.20-9.30$ & $9.35-9.50^{*}$ & $?$ \\
Matara & $9.15-9.25$ & $9.25-9.40$ & $9.40-9.50^{*}$ \\
Galle & $9.00-9.25$ & $9.30-9.45$ & $9.50 *$ \\
Hikkaduwa & $9.10-9.25$ & $9.40-10.00^{*}$ & $?$ \\
Beruwela & $9.45-9.55$ & $10.30-11.00$ & $11.30^{*}$ \\
Katukurunda & $9.40-9.50$ & $10.20-11.00$ & $11.30^{*}$ \\
Kalutara & $9.40-9.50$ & $10.50-10.10$ & $11.30^{*}$ \\
Panadura & 9.30 & 9.45 & $10.30-11.00^{*}$ \\
Moratuwa & 10.30 & 11.00 & $11.05-11.10^{*}$ \\
Mount Lavinia & 9.45 & $10.55-11.35^{*}$ & $12.10-?$ \\
Colombo & $9.15-9.30$ & $10.00-10.15^{*}$ & $12.10-12.25$ \\
\hline
\end{tabular}

- *Strongest wave - from eye-witness accounts and times of arrival in $\sim$ hours and minutes (local time a.m.)

- See Figure 2 for above locations 
diffracted, reflected and edge waves, where the second or third wave was the strongest (Table 1). A delayed (after $\sim 2$ hours) reflected wave component from the Maldives Archipelago, to the southwest of Sri Lanka was recorded by the tide gauge. This was the only wave of significance around $7.5^{\circ} \mathrm{N}$ latitude on the west coast (near Puttalam). The data presented in Table 1, which incorporated much of the coastline from the east to the west (Figure 2), suggested that locations near Colombo had two superimposed waves (one, a reflected wave from the Maldives), to form the third wave, the highest. As only Colombo Port had a tide gauge operating, much of the information presented in Table 1 relates to eyewitness descriptions (as was the case in most countries).

As expected a bay and headland, or promontory, are the geomorphic configuration ${ }^{5}$, which resulted in most destruction during the tsunami. A bay creates a funnellike effect, trapping the waves; a headland, where wave energy is concentrated by refractive processes, causes a wave wrap-around effect, as happened in the large ports of Trincomalee, Galle and other areas (Figure 2). Bays can act as a barrier against, or resonate with, the waves; this depends on the direction of wave approach and their impact. Wave heights and inundation distances increased significantly from the east, to the south and north, and from the west to the east along the south coast; they decreased progressively, from south to north, on the west coast (Figure 3). The northwestern coast of Sri Lanka (from $7.8^{0} \mathrm{~N}$ to $9.7^{0} \mathrm{~N}$ ), together with the southern

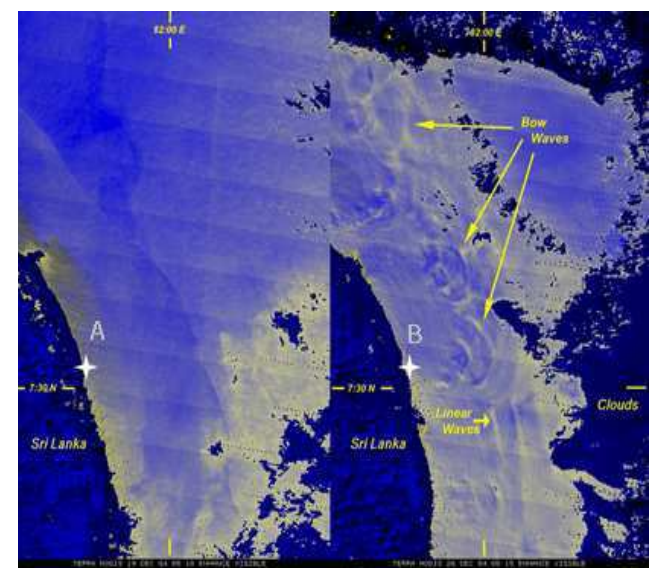

Figure 4: MODIS satellite images from Terra; A) one week before tsunami showing an undisturbed sea surface and B) two and a half hours after the tsunami struck the east coast of Sri Lanka showing the development of internal waves. Note the bow waves in the submarine canyons and linear waves on the slope margins. The star is the approximate location of the first major wave strike on the east coast (near Kalmunai), which lines up directly with a submarine canyon. (Courtesy of Dr. Dave Santek ) coast of peninsular India, were in the shadow zone with respect to adjacent landmasses; consequently they were unaffected by the waves (Figures 2 and 3 ).

With a narrow continental shelf, the friction and drag against the shoaling sea bottom caused the high speed waves to gain height as a high energy wall of water. This in turn entrained large volumes of sediment from nearshore areas and these were deposited as a sand-sheet on the coastal plain, covering an estimated area of $\sim 120-140 \mathrm{~km}^{2}$. A large and extensive boulder barrier built to prevent severe coastal erosion caused by coral mining, was broken through, with 0.5 to $1 \mathrm{~m}$ sized boulders strewn over $50 \mathrm{~m}$ inland and the wave inundating $800 \mathrm{~m}$ landwards (Figure 5). Generally, most parts of the coastline were damaged to varying degrees. However, the east coast of Sri Lanka was undoubtedly the worst affected, where entire villages were wiped out (Figure 6). These initial investigations have given a good insight into the behaviour of tsunami wave interactions as they impacted and swept around the island.

Much of the coastal zone of Sri Lanka is a highly permeable sand aquifer (porosities of 25-30\%), up to $2 \mathrm{~km}$ in width and several metres (up to $22 \mathrm{~m}$ ) thick. The inundated seawaters infiltrated the sand aquifer and were also dissipated into topographic lows, leaving very little water or nothing for the return flows. The greatest impact of the tsunami was on the drinking water resources of the coastal communities (over 50,000 wells destroyed). Two years after the event, the water was still undrinkable, despite four good monsoonal rainfall seasons ${ }^{6}$; by end of 2007 , about $55 \%$ of the wells registered some freshening; at the end of 2008 about $75 \%$ of the wells had freshened to "'pre-tsunami" levels. Drinking water quality was always poor in the coastal aquifers and is unlikely to improve due to prevailing hydrological conditions.

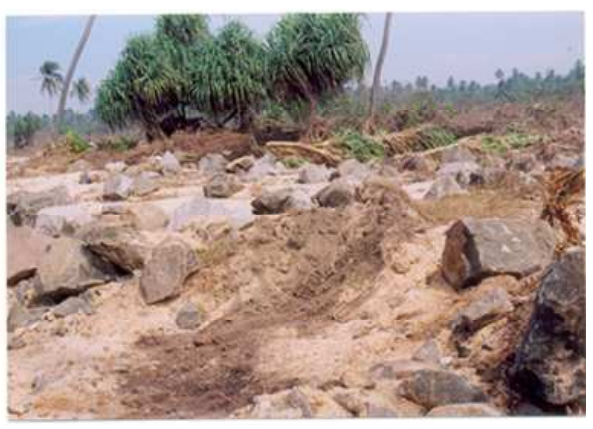

Figure 5: Erosional zone around the southwest coast ( $\sim 60$ m width), with breached stone barrier and large boulders strewn across the zone. Wave heights were $\sim 8 \mathrm{~m}$ here. Location: Akurala. 
The overall tsunami flow regime around Sri Lanka is summarized in graphic and pictorial form in Figures 2 to 6 . The results and interpretations are consistent with the theoretical considerations presented above. The 2004 megatsunami was a very low frequency, but very high intensity short duration event and hence the impact was catastrophic. These are very rare extreme oceanographic events (with a predicted return period of 500 to 1000 years and even longer in the Indian Ocean region). Capturing its scientific essence provided a rare opportunity.

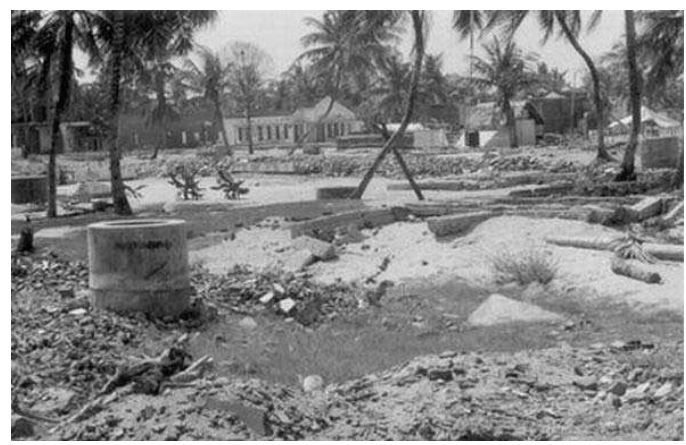

Figure 6: Almost total destruction of a coastal village. Wave heights were over $11 \mathrm{~m}$ here. Note cylindrical water wells. Location: Maruthamunai (East Coast, Amparai district).

\section{CONCLUSION}

A preliminary analysis of the overall flow regime of the 2004 tsunami around Sri Lanka is presented here and recorded for posterity. The $9.3 \mathrm{M}_{\mathrm{w}}$ Sumatra-Andaman earthquake and its rupture parameters and fault geometry are now known in great detail ${ }^{7}$. It is now the established calibration event in future studies of seismically induced tsunami. The size of the tsunami it generated is related to the amount of vertical displacement the earthquake imparted to the sea floor $(\sim 13 \mathrm{~m})$ and the directional properties of the seismic source. Consequently, the inferred flow regime $1600 \mathrm{~km}$ away in Sri Lanka is the resulting hydrodynamic response to that unique seismic event. The results of this study can be used in the preparation of tsunami hazard maps of the coastal zone, in disaster awareness and education programmes and in disaster preparedness. Further, numerical modelling studies and simulations of tsunami flow behaviour, especially in areas of shallow bathymetry for predictive purposes in disaster management, can be set against actual field data compiled in this study (Figure 3).

However, it is the sociological impact and humanitarian concerns resulting from this event that need to be emphasized. Besides the great economic damage and trauma resulting from this disaster and the total cutoff of drinking water supplies in the affected zone, it is clear that the top priority for the authorities is to have a planned back-up programme to provide clean drinking water for the affected communities over extended periods in case of a similar event in the future. This would prevent an epidemiological hazard. The wave record suggests that in the event of an early warning of an impending tsunami, the coastal communities should be advised by the local authorities to move to nearest high ground $>12 \mathrm{~m}$ elevation and /or walk inland as far as possible (2 km ?) in the time available for evacuation. This would minimize any potential loss of life.

\section{Acknowledgement}

The author especially wishes to thank C. Siriwardena and his team of geologists from the Geological Survey and Mines Bureau of Sri Lanka for generously supplying raw data of some of the field measurements. To Dr. Dave Santek (University of Wisconsin-Madison) for permission to use the NASA MODIS image. An earlier draft of the manuscript has been much improved by the critical comments of Prof. Mike Collins and Prof. Graham Evans.

\section{References}

1. Gunatilaka A. (2005). The Indian Ocean megatsunami of December 2004: the scientific basis of the catastrophe. Journal of the National Science Foundation of Sri Lanka 33(2): 69-80.

2. Merrifield M.E. et al. (24 authors) (2005). Tide gauge observations of the Indian Ocean tsunami, December 26, 2004. Geophysical Research Letters 32:Lo9603 doi:10.1029/2005GLO22610.

3. Liu P.L.F., Lynett P., Fernando H., Jaffe B., Fritz H., Higman B., Morton R., Goff J. \& Synolakis C. (2005). Observations by the international tsunami survey team in Sri Lanka. Science 308: 1595-1596.

4. United Nations Education, Scientific and Cultural Organization (1998). Post-Tsunami Survey Field Guide. IOC Manuals and Guides No. 37. Intergovernmental Oceanographic Commission, UNESCO, Paris.

5. Le Blond P.H. \& Mysak P.G. (1978). Waves in the Ocean. Elsevier, Amsterdam.

6. Illangasekera T., Tyler S.W., Clement T.P., Villholth K., Perera L., Obeysekera J., Gunatilaka A., Panabokke C.R., Hyndman D.W., Cunningham K.J., Kaluarachchi J., Yeh W-G., Van Genuchten M.T. \& Jensen K. (2006). Impact of 2004 tsunami on groundwaters in Sri Lanka. Water Resources Research 42(3) W05201,doi:10.1029/2006WR 004876.

7. Ammon C.J. et al. (13 authors). (2005). Rupture process of the 2004 Sumatra- Andaman earthquake. Science 308 : 1133-1138. 